\title{
El cumplimiento del Derecho a la Educación en tiempos de pandemia en el contexto costarricense
}

\section{Compliance with the Right to Education in times of pandemic in the Costa Rican context \\ O cumprimento do Direito à Educação em tempos de pandemia no contexto costarriquenho}

\author{
Dina Espinosa Brilla \\ Universidad de Costa Rica \\ San José, Costa Rica \\ dina.espinosa@ucr.ac.cr \\ (D) ORCID: https://orcid.org/0000-0002-7185-1481
}

Recibido - Received - Recebido: 23 / 03 / 2021 Corregido - Revised - Revisado: 23 / 05 / 2021 Aceptado - Accepted - Aprovado: 31 / 05 / 2021

DOl: https://doi.org/10.22458/ie.v23i34.3546

URL: https://revistas.uned.ac.cr/index.php/innovaciones/article/view/3546

\begin{abstract}
Resumen: Este trabajo aborda un análisis del cumplimiento del derecho a la educación de niños, niñas y adolescentes, frente a las dificultadas y las adaptaciones, que han emergido desde marzo de 2020 al presente, debido a la pandemia provocada por el virus responsable de la COVID-19. A partir del enfoque de derechos, se considerarán los principios que constituyen el derecho a la educación, con especial cuidado de su ejercicio en personas menores de edad. Se observarán algunos elementos que tengan injerencia en la gratuidad y la obligatoriedad, el acceso, la aceptabilidad, la adaptabilidad, en tanto condiciones inherentes del derecho a la educación, por medio de las estrategias remediales dirigidas por el Ministerio de Educación Pública de Costa Rica.
\end{abstract}

Palabras clave: Derecho a la educación; Pandemia; Educación pública; Políticas educativas; Estrategias remediales, Costa Rica

Summary: This work addresses an analysis of compliance with the right to education of children and adolescents, in the face of difficulties and adaptations, which have emerged from March 2020 to the present, due to the pandemic caused by the virus responsible for COVID-19. Based on the rights approach, the principles that constitute the right to education will be considered, with special care regarding how minors are able to exercise it. Some elements that have an influence on the gratuity and the mandatory nature, the access, the acceptability, the adaptability, as inherent conditions of the right to education, will be observed, through the remedial strategies directed by the Ministry of Public Education of Costa Rica.

Keywords: The right to education; Pandemic; Public education; Education policies; Remedial strategies, Costa Rica

Resumo: Este trabalho aborda uma análise do cumprimento do direito à educação que têm as crianças e adolescentes perante as dificuldades e adaptações que emergiram desde março de 2020 e até o momento presente devido à pandemia provocada pelo vírus responsável pelo COVID-19. A partir da abordagem dos direitos, serão considerados os princípios que constituem o direito à educação, com especial atenção ao seu exercício em menores. Serão analisados alguns dos elementos que têm ingerência na gratuidade e na obrigarietoridade , acesso, aceptabilidade, adaptabilidade, como condições inerentes ao direito à educação, por meio de medidas corretivas dirigidas pelo Ministério da Educação Pública da Costa Rica.

Palavras chave: Direito à educação; pandemia; edução pública; políticas educativas; medidas corretivas, Costa Rica 
La pandemia provocada por el virus responsable de la COVID-19 ha marcado un antes y un después en la vida del planeta, esto ha exigido distanciamiento social, incluso aislamiento, con el fin de poder parar las cifras de contagios y muertes; sin embargo, estas medidas drásticas no solo ha obligado a un desempeño de la educación a distancia (remoto y virtual), sino también han tenido que tomarse medidas de adaptación de manera rápida, y en especial, a reconstruir los procesos de enseñanza-aprendizaje, desde la distancia y con recursos tecnológicos limitados.

Según el Comité de Derechos Económicos, Sociales y Culturales (CODESC/ONU), el derecho a la educación se entiende como:

... un derecho humano intrínseco y un medio indispensable de realizar otros derechos humanos. Como derecho del ámbito de la autonomía de la persona, la educación es el principal medio que permite a adultos y menores salir de la pobreza y participar plenamente en sus comunidades (COSDEC, 1999. En Horbath y Gracia, 2016, p. 176).

De manera que, el derecho a la educación así como otros derechos fundamentales, se ha colocado en especial observación, por cuanto la conectividad ha venido a marcar problemas de accesibilidad y dificultades para hacer valer los principios que construyen el derecho a la educación.

En este caso, se analizarán las acciones que el Ministerio de Educación Pública (MEP) de Costa Rica ha ido tratando de resolver desde el 2020, para mantener el ejercicio del derecho a la educación en niños, niñas y adolescentes. Para lo anterior, se tendrán en cuenta los indicadores que ha publicado el MEP en relación con cobertura de la educación y las estrategias seguidas para el cumplimiento de este derecho. Cabe comprender que este es un avance de situación, el cual habrá que profundizar según evolucione la situación presente, pero desde ya se pueden ir señalando algunas consideraciones. Se ha tenido que recurrir a noticias y ruedas de prensa; pues no todos los datos estadísticos están disponibles al público de manera oficial en la página oficial del MEP.

\section{DESARROLLO DEL TEMA}

\section{La educación como derecho humano}

Los Derechos Humanos parten del reconocimiento del ser humano como ser digno, a quien le son inherentes derechos y condiciones que permitan su realización con plenitud. Desde la modernidad occidental, toma fuerza la universalidad de los derechos humanos, pero tras cuatro siglos, no se ha logrado consolidar este ideal. No obstante, el principal medio para alcanzar esta meta, así como el reconocimiento de la dignidad humana y todos los derechos que de allí se desprenden, está asociado al proceso educativo.

El derecho a la educación consiste en una estrategia para el desarrollo de las personas desde su infancia y a lo largo de sus vidas; pues permite el desarrollo de las personas en ámbitos cognitivo, social y cultural, y se desprende del ejercicio de la capacidad de aprendizaje de todo ser humano. Por lo tanto, por sí mismo, es un derecho, así como una herramienta para la posibilidad de cumplimento de otros derechos fundamentales.

Entre las condiciones inherentes al ser humano para su adecuado desarrollo, está su necesidad de aprender y educarse, no solo desde una perspectiva utilitarista, sino como parte integral de su desarrollo y 
su realización en la vida. Por ello, el derecho a la educación debe considerarse tanto como aspecto fundamental del desarrollo humano y también como instrumento para alcanzar el derecho a la libertad, al poder expresarse, participar en la toma de decisiones sobre sí mismo y sobre su entorno.

A partir de los señalamientos de la Organización de las Naciones Unidas (ONU, 1999 UNESCO, 2015, vid. Zumbado-Castro, M., 2019, pp. 109-110) las condiciones claves que posibilitan el ejercicio pleno del derecho a la educación son:

1. Disponibilidad: este principio implica que la oferta educativa incluya variedad de opciones para todas las edades, entre ellas, académicas y técnicas, ya sea formación básica o formación continua, con el fin de solventar las necesidades de la sociedad.

2. Accesibilidad: la educación debe estar al alcance de todos, por ello debe ser gratuita, inclusiva y con diseño universal en sus planteles, así como en el acceso a materiales y medios para acceder a ella. En el caso de la educación remota o a distancia, que existan los medios de conectividad de comunicación necesarios.

3. Adaptabilidad: la educación debe tener flexibilidad curricular y administrativa, para incluir a las personas según sus necesidades y prioridades.

4. Aceptabilidad: la educación requiere tener calidad y ser eficiente, además de poder ofrecer diversos métodos y planes de estudios con pertinencia cultural.

Estos cuatro requisitos básicos, se complementan con otras exigencias del derecho a la educación, que resumen Horbath y Gracia:

La realización del derecho educativo debe satisfacer, además de la cobertura, cualidades fundamentales tales como la obligatoriedad y gratitud, la calidad, la educación en derechos humanos, la libertad de los padres o tutores a elegir los centros escolares, la posibilidad de que personas privadas o jurídicas creen y dirijan centros escolares, el principio de no discriminación y la cooperación internacional. La gratuidad y obligatoriedad en los niveles fundamentales se debe acompañar de dotación o disponibilidad, accesibilidad, aceptabilidad y adaptabilidad (Horbath y Gracias, 2016, 176-177).

Las posibilidades para la realización de las personas y su rendimiento en la vida laboral también están ligadas al derecho a la educación, entendido como oportunidad para superar la pobreza. En particular, prima la importancia de que la educación implica destrezas para conocer, indagar, entender, y otras múltiples funciones lógicas y cognitivas del ser humano; es un proceso para aprender a aprender, para aprender a utilizar los conocimientos aprendidos y desarrollar estructuras cognitivas para generar nuevos aprendizajes.

De acuerdo con lo anterior, el aprendizaje es tanto proceso como producto de un sistema complejo, el cual orienta la toma de decisiones, la voluntad y la motivación que cada persona para hacer y desempeñarse en lo que mejor pueda, dentro de las circunstancias que se le presenten. El aprendizaje posibilita mejores oportunidades para enfrentar esas circunstancias. Este aspecto no debe perderse de vista en la situación de pandemia que vive el mundo en estos momentos.

La primera vez que se consigna el derecho da la educación fue en el artículo 26 de la Declaración Universal de los Derechos Humanos de 1948, en el cual se destaca la necesidad de una educación elemental gratuita, obligatoria, que permita el acceso a la formación técnica y profesional, así como que promueva un desarrollo respetuoso de las personas, los derechos humanos y la paz. Además, se destaca la prerrogativa de los padres, madres y tutores, a dar a sus hijos el tipo de educación de su preferencia. 
La Convención contra la Discriminación en Educación (UNESCO, 1960), enfatiza la accesibilidad a la educación de calidad para todos los grupos humanos, así como el adaptar la educación a cada estudiante. Costa Rica suscribe esta Convención y entra en vigencia con la Ley n. 3110 (12/08/1963).

El Código de la Niñez y la Adolescencia (Ley n. 7739, 1998), dedica el capítulo V al derecho a la educación para las personas menores de edad, con el fin de desarrollar sus potencialidades: "La preparación que se le ofrezca se dirigirá al ejercicio pleno de la ciudadanía y le inculcará el respeto por los derechos humanos, del ambiente natural, en un mar de paz y solidaridad" (artículo 56). Asimismo, el artículo 57 insiste en la permanencia de las personas menores de edad en el sistema educativo. La normativa de este capítulo V del Código habrá de reflejarse en la política educativa, para garantizar la universalidad de la educación desde los principios de educación gratuita y obligatoria, inclusiva y de calidad.

Con la entrada en vigencia de la Convención de los Derechos del Niño (CDN) (ONU, 1989), que Costa Rica suscribió (Ley n. 7184 del 26/01/1990), con el fin de hacer valer los derechos de los niños, niñas y adolescentes a pensar, decidir y expresar su juicio, en función de su edad y madurez, (art. 12), a la libertad de pensamiento, conciencia y religión (art. 14), así como la libertad de asociación (art. 15). Todo ello desde los principios de interés superior del niño y de su autonomía progresiva.

En el artículo 28, la CDN subraya el reconocimiento al derecho a la educación y su ejercicio progresivo y en condiciones de igualdad de oportunidades, Y, por otro lado, en el artículo 29.2 se insiste en mantener y respetar al menos las normas mínimas para la educación dadas por el Estado, las cuales garanticen el desarrollo de aptitudes y capacidades, el enfoque de derechos, el respeto y el aprecio por la cultura propia y las ajenas, y la responsabilidad para vivir en una sociedad libre, tolerante de la otredad, inclusiva y con igualdad de género. Además, la CDN prioriza el enfoque de derechos, como un elemento en el que el Estado debe asumir responsabilidades y garantías sobre el acceso a los derechos pro partes de los niños, niñas y adolescentes. El enfoque de derechos se puede definir como:

...es deber de los Estados respetar, promover y garantizar los derechos de las niñas, niños y adolescentes, además de prevenir, sancionar y reparar toda vulneración de los mismos. El rol de Estado da un giro, transformándose en garante principal de los derechos de todos los niños, niñas y adolescentes. Es el enfoque de derechos, entonces, el cimiento que sustenta la construcción de un sistema de monitoreo del ejercicio de los derechos [...] y el marco que guía la elección de variables e indicadores a ser incluidos. (Consejo Nacional de la Infancia, 2017, 9. En: IX Informe Estado de los Derechos de la Niñez y la Adolescencia en Costa Rica, 2019, p. 15).

Entre los Objetivos de Desarrollo del Milenio de las Naciones Unidas (ODM, 2000-2015), recalca el derecho a la educación como herramienta para "...erradicar la pobreza en el mundo y garantizar la existencia de un mundo desarrollado, justo y equilibrado" (ODM, objetivo 2, 2000). A la par de este compromiso de los ODM, hay que sumar el programa Educación para todos (EPT) de la ONU (2000), el cual prioriza que todos los niños y niñas logren terminar la educación primaria. En el 2014, se lanzan los Objetivos del Desarrollo Sostenible (ODS), también conocidos como metas globales (Global Goals), en los cuales se enfatiza la necesidad de: "Garantizar una educación inclusiva, equitativa y de calidad, y promover oportunidades de aprendizaje durante toda la vida para todos" (ODS, Objetivo 4, 2014). Este ODS 4 retoma los artículos 28 y 29 de la CDN, "el ODS 4 supone la inclusión de las minorías como valor social, de manera que o solo se respete la diferencia, sino que se incorporen con plenitud los derechos, y no se discrimine" (IX Estado de los Derechos de la Niñez y la Adolescencia en Costa Rica, 2019, p. 114).

Por consiguiente, el derecho a la educación no solo es reconocido; sino un derecho clave, el cual aspira a una cierta calidad y efectividad, que difícilmente se cumple y no por ello la educación deja de ser un factor determinante para el desarrollo de los individuos y la sociedad, tanto los organismos 
internacionales como la legislación nacional, enfatizan en su importancia, con especial atención en niños niñas y adolescentes.

\section{El derecho a la educación y los derechos de accesibilidad}

El derecho a la educación abarca más allá de los derechos sociales, económicos y culturales y pasa a ser pieza clave de los derechos de accesibilidad, a partir del concepto de "alfabetización digital", cuyo desarrollo supone una herramienta básica, que es la disposición de una conectividad eficiente. Tal como lo señala Cotino Hueso (2020)

...La importante Declaración conjunta sobre libertad de expresión e Internet de 1 de junio de 2011 (Naciones Unidas 2011 a) subrayó la "obligación positiva de facilitar el acceso universal a Internet" (n6a) y unos mínimos de acción. Se subraya la obligación de alfabetización digital, esto es, el deber de "promover la capacidad de todas las personas de efectuar un uso autónomo, independiente y responsable de Internet ("alfabetización digital")" (1.f). Se afirmaba expresamente que "El acceso a Internet también es necesario para asegurar el respeto de otros derechos, como el derecho a la educación" (6.a). (Cotino, Hueso, L. 2020, p. 12).

No es una novedad que las Tecnologías de la Información y la Comunicación (TIC) hace décadas que están al servicio de la educación, y la limitante no estriba en ellas mismas, sino en su accesibilidad. Por ello, la prioridad es mejorar la conectividad y la alfabetización digital. Para lograr lo anterior, a nivel internacional se han realizado diferentes esfuerzos, entre ellos: la cumbre de Ginebra (ONU, 2004) o la Agenda de Túnez (ONU, 2006).

Sin embargo, otro aspecto relevante consiste en que la vida del siglo XXI está muy imbuida en una sociedad cada vez más en estas tecnologías, al punto de consistir en formas de socialización fundamentales. En ese sentido, Cotino Hueso señala que "La educación debe lograr el pleno desarrollo de la personalidad, y ello hoy en día difícilmente puede lograrse sin la plena integración de las TIC en los procesos educativos" (Cotino Hueso, L., 2020, p,15).

El debate que debe preocupar para el ejercicio del derecho a la educación, cabe concentrarse en la equidad del acceso a las TIC en general, y en particular a internet de calidad y estable, que permita una cobertura real y eficiente de los usuarios. Esto es lo que Ruiz (2020) señala como un "acceso real" que permita "... la posibilidad de apropiación relevante de las tecnologías, en términos de formación de las personas, un acceso que debería ser equitativo, desde el enfoque del derecho a la educción, en la medida que favorezca aprendizajes equivalentes entro los estudiantes" (Ruiz, 2020, p. 55).

No se trata de desplazar la educación presencial, sino de entender que el derecho a la educación tiene diversas aristas, las cuales deben atenderse con el mismo interés y la alfabetización digital y la conectividad, tal como se viene desarrollando en la situación de pandemia, han sido herramientas de primer orden para mantener el ejercicio del derecho a la educación, y no deben constituir solo una salida alternativa, en cambio, son parte del ejercicio pleno del derecho a la educación.

\section{Educación Pública en Costa Rica: alcances y desafíos en época de pandemia}

En la Política Educativa La persona: centro del proceso educativo y sujeto transformador de la sociedad (aprobada por el Consejo Superior de Educación, acuerdo 05-55-2017, del 8/10/2017), se apoya en paradigmas, 
tales como: la complejidad, el humanismo, el constructivismo social y el racionalismo; y se centra en "...la calidad como principio nuclear que articula otros principios clave, como la inclusión y equidad, el respeto a la diversidad, la multiculturalidad y pluriculturalidad, la igualdad, la resiliencia y la solidaridad" (Consejo Superior de Educación, 2017, p. 10).

Todos estos principios se articulan en la intención de fomentar una formación para toda la vida, desarrollo de habilidades, destrezas y competencias, así como de actitudes y valores. Para ello, esta política educativa se articula en la educación centrada en el estudiante, basada en derechos humanos y deberes ciudadanos, -aunque no menciona el enfoque de derechos como tal, ni como eje transversal-, educación para el desarrollo sostenible y la ciudadanía planetaria con identidad nacional, evaluación transformadora para la toma de decisiones, en especial, con un desarrollo de la ciudadanía digital con seguridad social, que va a ser justo el eje en disputa en el período de pandemia que estamos viviendo (2020-2021).

En relación con este último eje de la política educativa vigente, se esperaría que tanto docentes como estudiantes, tuvieran un cierto aprendizaje del uso de las TIC, y este esfuerzo se constituyera en una estrategia para "cerrar la brecha digital, en todas las regiones del país. [...] Aprovechar responsablemente las tecnologías con fines educativos, productivos y personales, así como para la autogestión e incorporación de recursos" (Consejo Superior de Educación, 2017, p. 14).

De manera que, previo a la entrada en el aislamiento de por la pandemia (que en Costa Rica se da a mediados de marzo del 2020), ya debieron haberse desarrollado capacidades instaladas, desde la primera infancia, para la educación remota y virtual, en los docentes, los estudiantes y sus familias.

Ya en el IX Informe del Estado de los Derechos de la Niñez y la Adolescencia en Costa Rica (IX EDNA, 2019) se había señalado que:

La educación es un proceso que se asienta fundamentalmente en educación en valores, y por ello también el mejoramiento de las comunicaciones, la capacidad de transitar espacios distintos y el interactuar con personas diferentes, constituyen oportunidades que deberían reforzarse, ojalá, no solo por "conexión virtual". (IX EDNA, 2019, p. 95).

Por otra parte, el país ha apostado por una inversión fuerte en educación, concentrada en recursos para el MEP. En el 2018, la inversión en educación representó el segundo gasto más importante del total del gasto público total en niñez y adolescencia:

...más de la mitad del gasto en niñez y adolescencia -el 60,6\% - se dirigió hacia la función de educación. Mucho de esto se explica dado que dicha función comprende a la institución que más gasto realiza anualmente en el sector público costarricense que es el MEP, el cual dirige casi el $90 \%$ de su gasto a la población de personas menores de edad. (Contreras Ramírez, L., 2020, p. 58).

El gasto total para el 2018 representó 2669.0 miles de millones de colones, el equivalente a un 8,3\% del PIB, y un 19,9\% del gasto total del sector público no financiero (Contreras Ramírez, L, 2020, p. 57), lo que en promedio anual se traduce en casi dos millones de colones por personas menor de edad en el 2018 :

...los recursos públicos anuales promedio destinados por persona menor de 5 años se estimaron en 1,7 millones de colones, en 2,2 millones por persona menor de edad entre 6 y 11 años, y en 2,3 millones por persona menor de edad entre 12 y 17 años. (Contreras Ramírez, L., 2020, p. 58).

La inversión en educación para la niñez y la adolescencia es en rubro importante; no obstante, habría que analizar la eficiencia de esa inversión, y si en efecto, los requisitos de cobertura, calidad y equidad 
logran satisfacer a toda la población. Para ello, el MEP ya venía desarrollando estrategias como las pruebas FARO, mejorar el sistema de información, la calidad de los docentes, mejorar los sistemas de información con una red interactiva entre el MEP y las centros educativos, fortalecer la enseñanza de idiomas, de materias STEAM para secundaria, reducir la deserción intra-anual en III ciclo y Diversificada (MEP, 1919,b. en: PEN, 2019, p. 125). Esos rezagos en la calidad de la educación ya venían preocupando al MEP, y no todos los ha podido atender. Por ejemplo, en el IX EDNA, se indica que:

A partir de los niveles de reprobación, puede verse una falta de continuidad en el sistema educativo que hace difíciles los tránsitos en el séptimo y el décimo año; esto hace ver que las destrezas educativas desarrolladas son insuficientes para que los NNA pueda desarrollar aprendizajes en diferentes contextos (de la primaria a la secundaria, por ejemplo). (IX EDNA, 2019, p. 94).

La relación entre falta de educación formal y pobreza en Costa Rica, resulta evidente en el perfil de la pobreza que señala la Encuesta de Hogares Julio 2020 (INEC, 2020, pp. 65-66):

La dimensión de Educación está conformada por cuatro indicadores que toman en consideración las diferentes etapas de la vida y del ciclo educativo de las personas. De las privaciones consideradas en esta dimensión, la denominada Bajo desarrollo de capital humano es la de mayor incidencia (y la segunda entre todos los indicadores del IPM) pues está en el 63,3\% de estos, esto representa alrededor de 164 mil hogares. Sin cambio significativo respecto al 2019.

El indicador Sin logro de bachillerato está en el segundo lugar de privación. Afecta al 27,0\% de los hogares pobres [...] Los otros dos indicadores, Rezago educativo y No asistencia a la educación formal, presentan porcentajes menores, $15,2 \%$ y 5,6\% respectivamente. Rezago educativo aumentó, respecto al año anterior, en 2,0 pp., en tanto No asistencia a educación formal. Disminuyó 1,8 pp. en este período, esto último es estadísticamente significativo. (INEC, Encuesta de Hogares, 2020, p. 65).

En cuanto al Internet, una herramienta vital en la pandemia, para vincularse a los estudios, en todos los niveles, el INEC encontró que el indicador Sin conexión a Internet, está presente el 20,2\% de hogares pobres, muestra un aumento de 4,0 pp. en relación con el 2019 (INEC, 2020, p. 61). Sin embargo, en la región Huetar Caribe la incidencia es de un 29,9\% y la Huetar Norte de un 30,0\%.

A la anterior circunstancia, se suma el aumento en la tasa de desempleo, en octubre 2020 llegó a ser del 21,9\%,según el Instituto Nacional de Estadística y Censos. El componente económico se complica sumado al de falta de equidad: "Debe mejorarse el acceso a la educación y a la asistencia o conexión de los y las estudiantes de las zonas rurales, ya que éstas duplican la no asistencia en relación con las zonas urbanas" (IX EDNA, 2019, p.94).

De acuerdo con el MEP, la cobertura educativa no disminuyó de manera sensible en el curso 2020, a pesar de las restricciones sanitarias que obligaron al cambio a educación remoto o virtual (MEP/noticias, 15/12/2020). Las estrategias que el MEP mantuvo fueron guías de trabajo autónomo (1.200 guías virtuales e impresas), actualización docentes (capacitación a más de 60 mil educadores mediante plataformas virtuales), uso de plataforma virtual TEAMS (gratuita) y correo electrónico; apoyos audiovisuales difundidos, tales como Aprendo en Casa Primera Infancia, Plaza Sésamo, Aprendo en Casa TV, jJuguemos!; Aventura Biketso, Vocación docente radio y entrega de materiales en lenguas indígenas. 
Para mayo de 2020, el MEP estimó un acceso a Internet en los siguientes téminos:

\begin{tabular}{lcc}
$\begin{array}{c}\text { Condición de Internet en el hogar del } \\
\text { estudiante }\end{array}$ & $\begin{array}{c}\text { Número de } \\
\text { estudiantes }\end{array}$ & Porcentaje \% \\
\hline Tiene Internet en su hogar & 680088 & 63,3 \\
No tiene Internet en su hogar & 324616 & 30,2 \\
Sin información por parte del centro educativo & 68979 & 6,4 \\
Total de estudiantes & 1073683 & 100,00 \\
\hline
\end{tabular}

Fuente: elaboración propia con los datos de MEP (2020).

Como resultados de cobertura, el MEP reportó una tasa bruta y una tasa neta de escolaridad, los cuales no presentan una gran diferencia entre el 2020 y el 2019 (variación entre uno a dos pp.). Pero debe hacerse la salvedad que se dieron huelgas en el magisterio en el 2018 (93 días) y el 2019 (86 días), que ya venían generando adaptaciones en el ciclo lectivo (ver Figura 1).

Figura 1. . Tasas brutas de escolaridad en el sistema educaativo tradicional, según nivel de enseñanza, periodo 2010-2020

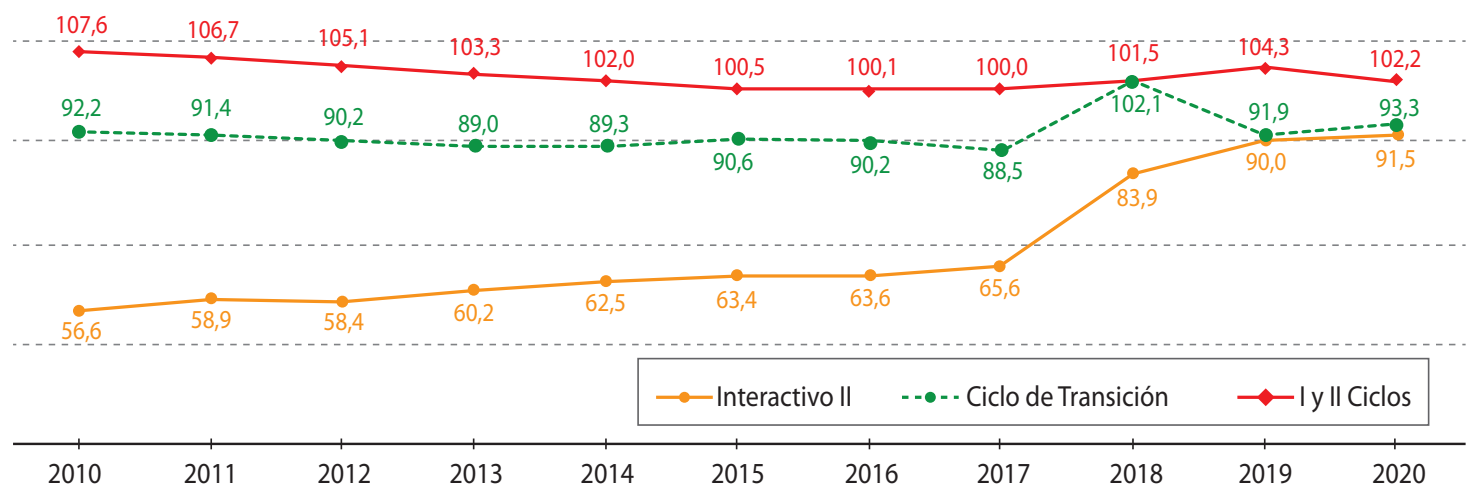

Fuente: MEP, 2021, p. 20

El año lectivo inició en febrero y los cierres por pandemia se dieron alrededor de un mes después; por lo tanto, no se ve una variación significativa en la matrícula del curso 2020. La tasa bruta de matrícula que refleja el número de estudiantes matriculados por nivel sin tener en cuenta la edad, ni la educación secundaria (tasa bruta de 105 en el 2019 a 104,7 en el 2020), ni en el III ciclo (tasa bruta de 104,7 en el 2019 y 102,1 en el 2020), ni en la educación Diversificada (tasa bruta de 105,5 en el 2019 a 108,7 en el 2020), se presentó una variación significativa. Las edades a las que corresponden la matrícula según los ciclos son: interactivo II 4 años, ciclo de transición 5 años, I y ll ciclos de 6 a11 años, y secundaria de 12 a 16 años.

En cuanto a la tasa neta de escolaridad, la cual refleja el número de estudiantes correspondiente a cada nivel según su edad, se encontró que se sostuvo la mejoría en la matrícula del Interactivo Il, que venía mejorando significativamente desde el 2017 (ver figura 2). La educación secundaria, en cambio, declinó en forma leve y la primaria se mantuvo. 
Figura 2. Tasas netas de escolaridad en el sistema educaativo tradicional, según nivel de enseñanza, periodo 2010-2020

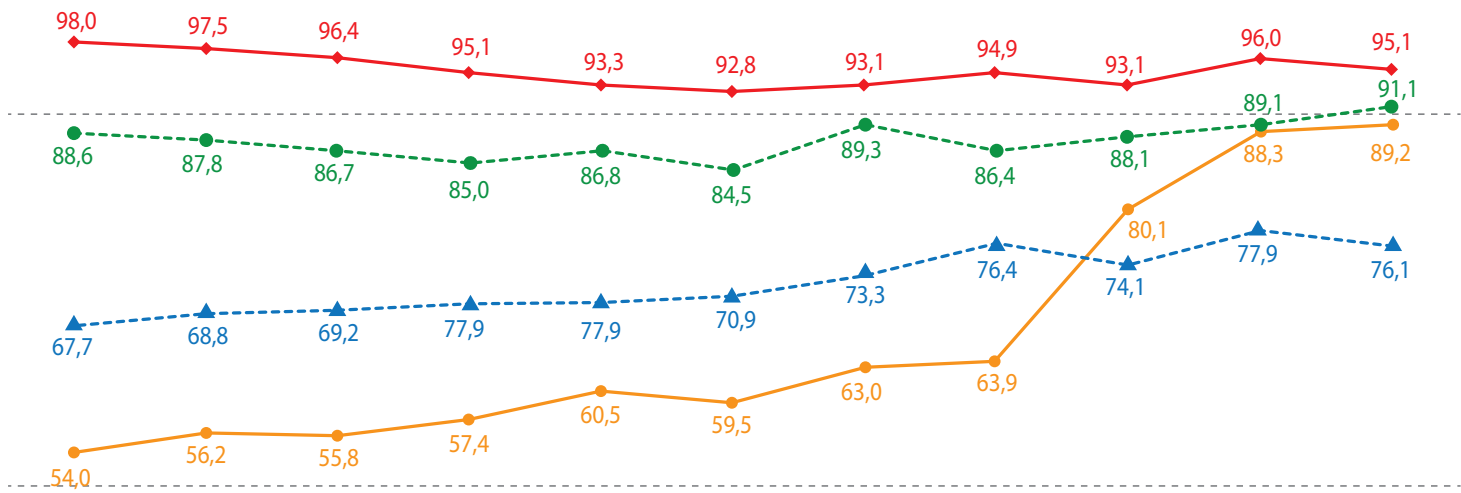

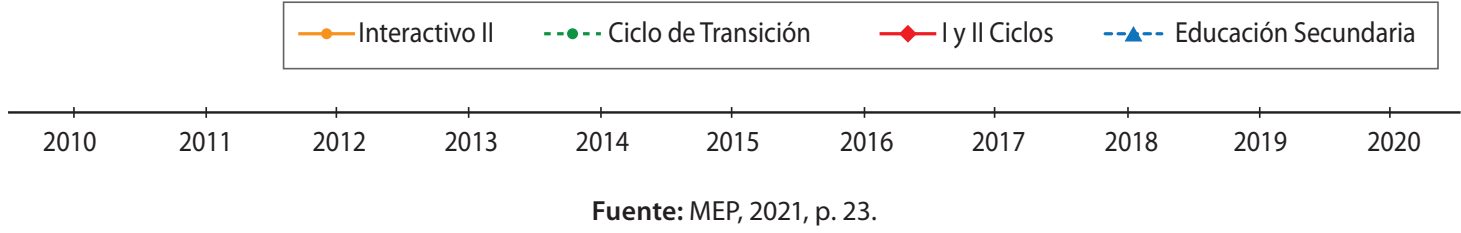

Por otra parte, la afectación que ocasionó la pandemia, debió ir marcándose en la segunda mitad de 2020. Pese a todas las dificultades (económicas, de conectividad, de movilidad) presentadas por la pandemia, el MEP (MEP, 2020) indicó que de 1.185.294 de estudiantes censados, el 95\% de los estudiantes matriculados en el curso lectivo lograron mantenerse vinculados. No obstante, MEP dejó a 16.065 (un $1,45 \%$ estudiantes matriculados quedaron excluidos en el ciclo lectivo 2020). Las regiones con mayor exclusión fueron San Carlos (2.621 estudiantes), Heredia (2.022), Alajuela (1.891) y Guápiles (1.045) (Villalta, P., 2020). La mayor parte de los estudiantes son de secundaria, colegios académicos y nocturnos (10.000 estudiantes).

La situación de pandemia obligó a una transformación curricular con carácter de urgencia y la búsqueda de estrategias y recursos,. Entre estos esfuerzos se habilitó la plataforma de Microsoft Teams (video conexión), de la cual forman parte (a diciembre de 2020) 721.831 usuarios activos. Los centros educativos prestaron 86.257 computadoras y 9.479 tabletas a los estudiantes. Se construyó una estructura para habilitar la educación que es la Plataforma Sistema de Administración Básica de la Educación y sus Recursos (Plataforma SABER), como parte de la Red Bicentenario (se espera completar en agosto 2021), con el fin de minimizar la brecha tecnológica en el sistema educativo.

La búsqueda de apoyos diversos dio lugar a la búsqueda de enlaces estratégicos con instituciones nacionales, internacionales, públicas y privadas, tales como: Instituto Costarricense de Electricidad, Microsoft, Banco Centroamericano de Integración Económica, Fundación Omar Dengo, Fundación Quirós y Tanzi y la Fundación Teach United.

Por medio del Programa de Equidad del MEP, se beneficiaron 850.000 personas con los 8,5 millones de paquetes de alientos entregados en la 27 Direcciones Regionales de Educación (del 24 de marzo al 18 de diciembre de 2020). También se aprovechó para mejoras de infraestructura con 79 obras que beneficiarán a unos 70 mil estudiantes en todas las modalidades de estudio (MEP, 2020). Por último, se formula la estrategia de vuelta a clases presenciales, con los protocolos y los cuidados necesario en el 2021. Sin embargo, tras casi cuatro meses, se ha requerido un nuevo cierre, por el aumento vertiginosos de contagios en el país. 
La estrategia de retornar a clases presenciales, de manera bimodal, que se acuñó como la Estrategia Regresar, se basó en las condiciones de exclusión y dificultades de aprendizaje que se experimentaron en el 2020:

La evaluación final del curso 2020, permitió al MEP reconocer que un número considerable de personas estudiantes concluyeron el año lectivo con bajos niveles de logro en la adquisición de conocimientos; esta realidad ha sido conocida en la información emanada de las regiones educativas al reportar las personas estudiantes que deberán presentar estrategias de promoción en febrero del

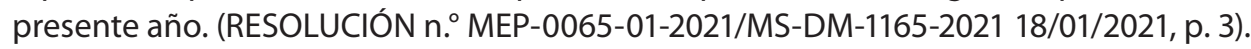

En cuanto al bajo rendimiento de los estudiantes, el MEP señala que las causas son "... la diversidad de escenarios económicos, familiares e individuales y de capacidad cognitiva" (RESOLUCIÓN n. ${ }^{\circ}$ MEP0065-01-2021/MS-DM-1165-2021 18/01/2021, p. 7). El MEP también señala la pérdida de interacción social como un elemento más que sumar a los bajos rendimientos y como un factor que puede afectar la salud mental de los estudiantes.

Por otra parte, el proyecto Estado de la Nación, en su artículo Brecha digital y desigualdades territoriales afectan acceso a la educación (21/07/2020), destacó que un 29\% de los hogares tiene conexión a internet únicamente por medio de telefonía celular, y un 3\% no tiene ninguna conexión. Y en las regiones Huetar Caribe, Huetar Norte y Brunca alrededor del $40 \%$ de los hogares se conecta con telefonía celular y el $10 \%$ no tiene conexión.

No solo se trata de la conectividad de los estudiantes, sino la de los mismos docentes; pues en las regiones Huetar Caribe y Huetar Norte, los docentes solo tienen telefonía celular para conectarse a Internet. La falta de equipo de cómputo también es un agravante para docentes y educandos.

A pesar de los esfuerzos realizados por el MEP, cabe destacar que la brecha tecnológica se evidenció por la necesidad del trabajo y estudio a distancia, pero que ha aumentado a la par de la falta de equidad creciente en el país. A estas limitaciones debe agregarse la calidad de la señal de Internet y la contratación del servicio; pues una conexión de calidad que permita mantener videoconferencia y al menos unas haya cuatro personas (entre laborando y estudiando de forma remota) conectadas a la vez, no es económicamente asequible, ni está garantizada la calidad de la señal de Internet que pueda dar esa cobertura, ni siquiera en la región central. La fibra óptica es la opción menos accesible, seguida por el cable coaxial o por teléfono celular, sin olvidar el sector sin ningún tipo de conexión.

El MEP y las comunidades habían hecho esfuerzos importantes para dotar de equipo de cómputo a escuelas y colegios; sin embargo, con el confinamiento de los estudiantes en sus casas, el equipo está en desuso y expuesto a robos (como ha pasado especialmente en la región Chorotega). La brecha tecnológica ha ido aumentando, al punto que le MEP señaló que unos 400.000 estudiantes no tienen conexión a Internet. Las zonas más afectadas son los cantones de Upala (79\%), La Cruz (72\%) y Garabito (70\%); además, se recalca que los problemas de la lentitud o falta de señal son múltiples hasta en la región Central (CRHoy, 20/05/2021).

Por lo anterior, la situación económica agravada por la pandemia, la falta de una infraestructura adecuada para la conectividad y cobertura con calidad de servicio en todo el país, son elementos que no se han podido solucionar y persisten como obstáculos para el buen desarrollo del curso lectivo. No obstante, los estudiantes presentaron un rendimiento bajo también por factores educativos específicos; por ejemplo, "el MEP cuenta con 25.000 docentes, pero en 10 años, únicamente en 3.731 escuelas (el 89\% de la totalidad de los centros educativos del país) ofrece el currículum completo" (IX EDNA, 2019, p. 94). 


\section{SÍNTESIS Y REFLEXIONES FINALES}

La viabilidad de la educación remota, apoyada en medios digitales, es realmente deficiente en un país que aumenta su falta de equidad, $y$, como consecuencia, se ponen en riesgo el ejercicio a derechos humanos básicos y fundamentales como la educación.

Desde el punto de vista del enfoque de derechos, las deficiencias en conectividad y la calidad de la educación, implican que el Estado debería ser más eficiente para atender elementos que lesionan el derecho a la educación. En cuanto al principio de disponibilidad, el aislamiento, por motivo de la pandemia, cercenó las opciones educativas que habías y redujo la oferta a la educación a distancia, las opciones de clases virtuales, programas de televisión de apoyo, y entrega de materiales impresos; pero no fue suficiente para generar autogestión del aprendizaje.

Es obvio que no había una preparación para ello de los educandos, ni de los padres o cuidadores, en especial con los niños y las niñas de menor edad, que aún están en formación para aprender a aprender. Tampoco se podía esperar que los padres y los cuidadores pudieran ayudar en el proceso de aprendizaje, de una manera más protagónica de lo usual; pues la escuela ha servido de espacio para el cuidado de los niños y las niñas; mientras los padres trabajan y esta realidad no puedo solventarse de ninguna otra forma. Por consiguiente, no se dieron variedad de opciones para un proceso de enseñanza-aprendizaje sostenido, homologable a las prácticas instaladas en la educación presencial.

Por otra parte, la accesibilidad resultó el principio más vulnerado del derecho a la educación. La obligatoriedad tampoco pudo cumplirse; pues no se dieron los recursos para acceder a la educación. Si bien la gratuidad en Costa Rica opera para la matrícula y se brinda apoyo de alimentación, traslados, uniformes y otros gastos se vieron reducidos, pero no compensaron los gastos por inversión en tecnología y conexión a Internet de manera apropiada, para dar seguimiento al curso lectivo. La inclusividad también se ha visto afectada, en particular en los casos en los que los estudiantes requieren apoyos y materiales particulares, como por ejemplo, dispositivos especiales para personas sordo-ciegas.

El MEP hizo grandes esfuerzos para la adaptabilidad, se reacomodaron los cursos lectivos, se apoyó al docente con capacitaciones y se flexibilizan aspectos curriculares, como centrar el curso en objetivos de aprendizaje y destrezas y no en contenidos. De los cuatro principios del derecho a la educación, este es el que más se trabajó desde la administración, pero la modalidad virtual no pudo desarrollarse bien en ningún momento, porque el principio de accesibilidad fue deficiente.

Con respecto al principio de aceptabilidad, lo cual implica calidad y eficiencia de la educación, solo se podría afirmar la disparidad y la brecha entre estudiantes con conexión y los que no la tienen. Lograr una educación de calidad supone una preparación tanto de los docentes como de los propios estudiantes y de sus padres o cuidadores; pues requiere de destrezas de aprendizaje que, por lo visto, no estaban instaladas, lo cual se refleja en el bajo rendimiento de los estudiantes. Entre estos aspectos está la organización del tiempo, la disciplina de estudio, el espacio adecuado para la concentración, y los recursos tecnológicos le sean propios y el tiempo necesario. Pero en muchos casos, los estudiantes tenían que desplazarle a lugares con señal de Internet, o bien, solo podía utilizar los recursos en horarios limitados, por tener que compartirlos con otros miembros de la familia.

Se puede resumir la falta del ejercicio al derecho a la educación en falta de cobertura y equidad; pues a pesar de que la matrícula no disminuyó sensiblemente, la posibilidades de los estudiantes de realizar un curso con calidad y eficiencia, no fueron suficientes. La responsabilidad es compartida entre la administración, los docentes, los estudiantes y los padres y cuidadores. Para los docentes las dificultades mencionadas de acceso a Internet y equipo de cómputo son relevantes. Sin embargo, lo peor es la falta de conectividad estable, rápida y segura, lo cual apunta a un rezago estructural en el país. En este aspecto, aunque los docentes y los estudiantes tuvieran equipos y conexión (sin contar con los problemas 
económicos que han sufrido muchas familias en esta pandemia), la calidad de la señal es deficiente y eso imposibilitó el buen desempeño del proceso educativo, incluso en la región central del país.

Por lo tanto, el ejercicio del derecho a la educación, durante el 2020, ha dejado más dudas que aciertos; pues el país no estaba preparado para poder garantizar con equidad el cambio obligado a la educación remota de manera rápida y masiva.

\section{REFERENCIAS}

Código de la Niñez y la Adolescencia. (1998). República de Costa Rica. Ley №7739.

Contreras Ramírez, L. (2020). Desarrollo de una propuesta metodológica y de una hoja de ruta para la medición de los recursos destinados a la niñez y la adolescencia en Costa Rica: Principales resultados del proyecto. Universidad de Costa Rica/Instituto de Investigaciones en Ciencias Económicas. https:// vinv.ucr.ac.cr/sigpro/web/researchers/114950721

Cotino Hueso, L. (2020) La enseñanza digital en serio y el derecho a la educación en tiempos de coronavirus. Revista de Educación y Derecho. (21):2-29. DOI: http://doi.org/10.1344/REYD2020.21.31283.

CRHoy. (2021). Ministra de Educación: "Problemas de conectividad son muy grandes. Cr.Hoy. Sección Nacionales: Educación. https://www.crhoy.com/nacionales/ministra-del-mep-problemas-de-conectividad-son-muygrandes/\#: :text=(CRHoy.com)\%20.,gran\%20brecha\%20 tecnol\%C3\%B3gica\%20del\%20pa\%C3\%ADs.

Horbat, J.; Gracia, M. (2016). El derecho a la educación: Un análisis a partir de la política educativa de las dos últimas décadas en México. Revista de Relaciones Internacionales, Estrategia y Seguridad. 11(1):171-191. DOI: http://dx.doi.org/10.18359/ries.1373.

Instituto Nacional de Estadística y Censos. (2020). Encuesta Nacional de Hogares Julio 2020. Resultados generales [recurso electrónico] E /Año 9. https://www.inec.cr/sites/default/files/documetos-biblioteca-virtual/renaho2020.pdf

Ministerio de Educación Pública. (2020). Conferencia de prensa. https://www.mep.go.cr/noticias/ mas-95-estudiantado-continua-vinculado-sistema-educativo-pesar-covid-19

Ministerio de Educación Pública. (2021). Resolución MEP-0065-2021(18/01/2021).

Ministerio de Educación Pública/Departamento de análisis estadístico. (2021). Indicadores del sistema educativo costarricense. 2010-2020. MEP, Publicación Nº 415-21.

Organización de las Naciones Unidas (1948). Declaración Universal de los Derechos Humanos. https://www.un.org/es/documents/udhr/UDHR_booklet_SP_web.pdf

Organización de Isa Naciones Unidas (1989) Convención de los Derechos del Niño. ONU https://www.un.org/es/events/childrenday/ pdf/derechos.pdf

Organización de las Naciones Unidas/Consejo Económico y Social. (1999). Aplicación del Pacto Internacional de Derechos Económicos, Sociales y Culturales. E/C.12/1999/10 8 de diciembre de 1999. https://www.refworld.org/cgi-bin/texis/vtx/rwmain/opendocpdf. pdf?reldoc $=y \& d o c i d=47 e b c c 8 e 2$

Organización de las Naciones Unidas para la Educación, la Ciencia y la Cultura (UNESCO). (2015). Resultados del foro mundial sobre la educación 2015. https://unesdoc.unesco.org/ark:/48223/ pf0000234002_spa.

Organización de Naciones Unidas para la Educación, la Ciencia y la Cultura (UNESCO)/Etxea (2005). La educación como derecho humano. Euskadi, Centro UNESCO Euskal Herria. 
Programa Estado de la Nación en Desarrollo Humano Sostenible (2020). Brecha digital y desigualdades territoriales afectan acceso a la educación. https://estadonacion.or.cr/ brecha-digital-y-desigualdades-territoriales-afectan-acceso-a-la-educacion/

Programa Estado de la Nación en Desarrollo Humano Ssotenible (2019). Estado de la Educación. PEN, $7^{\circ} \mathrm{ed}$. Marterlito.

Semanario Universidad. (2020). Entrevista a Paula Villalta, Viceministra de Planificación y Coordinación Regional del MEP. Semanario Universidad. Sección País.

Universidad de Costa Rica/Fondo de las Naciones Unidas para la Infancia (2019). IX Informe Estado de los Derechos de la Niñez y la Adolescencia en Costa Rica (IX EDNA). Proyecto EDNA. http://www.edna. ucr.ac.cr.

Zumbado-Castro, M. (2019). Educación como derecho humano, perspectiva desde la educación matemática costarricense. Revista Ensayos Pedagógicos. XIV(2):107-125. 